\title{
Penicillin in Prevention of Tetanus
}

\author{
J. W. G. SMITH,* M.B., M.C.PATH., DIP.BACT.
}

While there is no doubt that active immunization is the ideal method of preventing tetanus, consideration must be given to other methods for use at the time of wounding in patients who have not been immunized. The procedure widely used at the present time involves a combination of surgical cleansing of the wound, together with an injection of tetanus antitoxin prepared from horse serum. The importance of surgery is not doubted, although there is little experimental or field evidence of its value (Bruce, 1920 ; McDonald, Chaikof, and Truant, 1960). On the other hand, the use of antitoxin is often criticized, partly on account of its association with hypersensitivity reactions, and also because its effectiveness in man has never been conclusively proved (Cox, Knowelden, and Sharrard, 1963). Consequently efforts are being made to replace horse antitoxin with either human gamma-globulin containing tetanus antitoxin, which is not yet available in Britain, or with antibiotics.

Antibiotic prophylaxis has already been adopted in place of antitoxin in a number of centres (Filler and Ellerbeck, 1960 ; Cox et al., 1963) and apparently has not resulted in an increase in the incidence of tetanus. This probably indicates that, provided surgical care is of a high standard, antibiotics may be acceptable for the majority of patients in regions where tetanus is rare. There has, however, been no true comparison of the relative effectiveness of antibiotics and antitoxin, and it would be difficult, since tetanus only very rarely occurs after the use of prophylactic measures, to make such a comparison. The effectiveness and limitations of antibiotic prophylaxis must therefore be judged, at the present time, from laboratory experiments.

A number of investigations have shown that experimental tetanus infection can be controlled with antibiotics, although complete protection was not always achieved (Evans, Fuller, and Walker, 1945 ; Novak, Goldin, and Taylor, 1949 ; Bliss, Warth, and Chandler, 1950 ; Lennert-Petersen, 1954 ; Anwar and Turner, 1956). Studies have also been made of the action of antibiotics on a number of strains of Clostridium tetani in culture, and, although most strains were found to be sensitive to inhibition, resistance was encountered, particularly in the case of streptomycin (Lindberg and Newton, 1954 ; Garrod, 1958 ; Scheibel and Assandri, 1959a). In the present paper experiments are reported which show that in order to achieve successful control of experimental tetanus infection with penicillin a number of factors must be taken into consideration.

\section{Materials and Methods}

Cl. tetani Spore Suspension.-A virulent strain of Cl. tetani, T.67, was grown on nutrient-agar plates and incubated at $37^{\circ} \mathrm{C}$. for two weeks. The surface growth was removed, washed twice in normal saline by centrifugation, and heated to $80^{\circ} \mathrm{C}$. for 20 minutes to inactivate free toxin and to kill vegetative bacilli. The viability of the preparation was determined by means of colony counts of dilutions incubated for 48 hours in Brewer's medium containing $0.25 \%$ agar.

Experimental Infection.-White mice weighing between 16 and $21 \mathrm{~g}$. were injected with a minimum lethal dose of spores

\footnotetext{
* Senior Lecturer in Bacteriology, London School of Hygiene and Tropical Medicine.
}

freshly suspended in $0.2 \mathrm{ml}$. of $2.5 \%$ calcium chloride into the muscles of the right thigh. The minimum lethal dose was determined by titrating a tenfold series of dilutions in groups of mice, and contained approximately 250 colony-forming units. The resulting infection caused ascending tetanus with symptoms first noticeable in the injected leg 16 to 24 hours after injection and proving fatal 20 to 48 hours later.

Penicillin.-The following preparations were used: benzathine penicillin ; a mixture of benzathine, procaine, and benzyl penicillins in the proportions 2:1:1 (Penidural All-Purpose); benzylpenicillin. Both long-acting penicillin preparations were injected in appropriate dilutions into the muscles of the left thigh of mice in a volume of $0.05 \mathrm{ml}$., using an Agla micrometer syringe fitted with a needle of $0.45 \mathrm{~mm}$. diameter. The required dose of benzylpenicillin was injected subcutaneously in a volume of $0.2 \mathrm{ml}$.

Penicillin Assay.-The penicillin, content of serum samples from mice was assayed by an agar-diffusion method using Sarcina lutea as an indicator (Welch, 1948). Dilutions of standard penicillin were made in $\mathrm{pH} 6$ phosphate-buffered saline, instead of normal serum, with the aim of estimating free rather than total serum penicillin.

Penicillin Sensitivity Tests.-These were made with 2-week cultures of $\mathrm{Cl}$. tetani in cooked-meat broth. The cultures contained approximately $3 \times 10^{6}$ organisms $/ \mathrm{ml}$., of which $3 \times 10^{5} / \mathrm{ml}$. were spores. Approximately $6 \times 10^{3}$ organisms were added to each of six tubes of Brewer's medium containing $0.1 \%$ thioglycollate, the tubes being held at $50^{\circ} \mathrm{C}$. in order to obtain uniform distribution of the inoculum. The tubes contained different concentrations of penicillin ranging initially from 0.02 to 2 units $/ \mathrm{ml}$., and control tubes containing no penicillin were included. The penicillin was added to the medium immediately before the bacteria, the total time at $50^{\circ} \mathrm{C}$. being approximately 10 minutes, which was shown to have no detectable effect on the concentration of penicillin. The cultures were then cooled to $37^{\circ} \mathrm{C}$., incubated for eight days, and examined daily for visible growth. The decline in penicillin concentration occurring in Brewer's thioglycollate medium incubated at $37^{\circ} \mathrm{C}$. was found by titration to be approximately $50 \%$ a day. It was appreciated that this decline was faster than would have occurred in the absence of thioglycollate, but the object was not only to test the sensitivity of strains of $C l$. tetani to a particular initial concentration of penicillin but also to investigate whether strains would survive and grow later when the penicillin concentration had fallen.

Tetanus Antitoxin.-Pepsin-refined antitoxin (Wellcome) containing 1,500 units $/ \mathrm{ml}$. was used.

\section{Action of Penicillin on Cl. tetani in Culture}

The penicillin sensitivity of 22 strains of $\mathrm{Cl}$. tetani from the National Collection of Type Cultures was examined and the results are given in Table I. After 24 hours' incubation, growth of all the strains was found to be inhibited in those tubes initially containing $0.05 \mathrm{unit} / \mathrm{ml}$. On continued incubation, as the penicillin concentration declined, growth appeared in many of the culture tubes as indicated in the Table. All 132 tubes were subcultured on the eighth day into cooked-meat broth and all except three yielded growth of $\mathrm{Cl}$. tetani. 
TABLE I.-In vitro Sensitivity to Penicillin of 22 Strains of Cl. tetani

\begin{tabular}{c|c|c|c|c|c|c|c}
\hline & \multicolumn{6}{c}{$\begin{array}{c}\text { No. of Days' } \\
\text { Incubation }\end{array}$} & \multicolumn{6}{c}{$\begin{array}{c}\text { No. of Strains Showing Visible Growth in Broth Initially } \\
\text { Containing Penicillin Concentrations (unit/ml.) cf: }\end{array}$} \\
\cline { 2 - 8 } & 0 & 0.02 & 0.05 & 0.1 & 0.5 & 1 & 2 \\
\hline 1 & 22 & 9 & 0 & 0 & 0 & 0 & 0 \\
2 & 22 & 18 & 3 & 1 & 0 & 0 & 0 \\
4 & 22 & 21 & 8 & 2 & 1 & 0 & 0 \\
8 & 22 & 22 & 17 & 8 & 1 & 0 & 0 \\
\hline
\end{tabular}

The growth could not be attributed to the emergence of resistant mutants, but was apparently due to organisms which survived exposure to penicillin and grew as the concentration fell. The virulence and penicillin-sensitivity of organisms which had survived in tubes initially containing 2 units of penicillin were examined in the case of six of the strains and were found to be the same as the original strains.

It therefore seems that a proportion of the $\mathrm{Cl}$. tetani organisms in a culture can survive exposure to penicillin unchanged. Such surviving organisms resemble streptococcal "persisters" (Bigger, 1944) and may include L forms (Dienes, 1950 ; Scheibel and Assandri, 1959b). The ability of a significant proportion of organisms in a culture of $\mathrm{Cl}$. tetani to survive in penicillin or tetracycline has also been reported by Scheibel and Assandri (1959a).

\section{Action of Penicillin on Cl. tetani Infection in Mice}

The effect of a single dose of benzylpenicillin in protecting against tetanus was examined by injecting six groups each of five mice with different doses of benzylpenicillin, ranging from 200 to 10,000 units, immediately after injecting tetanus spores. All 30 mice died of tetanus, although in those given the larger doses of penicillin the onset of tetanus was delayed, for example until 60 hours in the case of the 10,000-unit dose. This observation suggested that a more prolonged treatment was necessary in order to control infection. Consequently the effect of various doses of long-acting benzathine penicillin was examined and the results are given in Table II. It was found that 1,000 units were required in order to achieve complete protection, although smaller doses, as with benzylpenicillin, were found to delay the onset of tetanus.

TABLE II.-Effect of Benzathine Penicillin in Mice Infected with

\begin{tabular}{c|c|c}
$\begin{array}{c}\text { Units of Benzathine } \\
\text { Penicillin Injected }\end{array}$ & $\begin{array}{c}\text { Proportion of Infected } \\
\text { Mice Surviving }\end{array}$ & $\begin{array}{c}\text { Average No. of Hours after } \\
\text { Infection when Tetanus } \\
\text { Developed }\end{array}$ \\
\hline 0 & $0 / 8$ & 22 \\
100 & $0 / 8$ & 48 \\
250 & $2 / 8$ & 84 \\
500 & $4 / 8$ & 102 \\
750 & $5 / 8$ & 127 \\
1,000 & $8 / 8$ & - \\
\hline
\end{tabular}

Further experiments were made to determine the duration of penicillin treatment and the serum concentration of penicillin necessary to control experimental infection. With benzylpenicillin, and giving two daily injections each of 800 units for a period of seven days after infection, it was found that only $50 \%$ of mice survived, whereas a single dose of 1,000 units of benzathine penicillin had given complete protection. An experiment was therefore performed in which mice were injected each with 10,000 units of benzathine penicillin and at intervals afterwards some were bled for serum penicillin assay and others were infected with tetanus spores which had been shown to be inhibited in vitro by 0.05 unit of penicillin per $\mathrm{ml}$. The results are given in Table III and illustrated in the Chart.

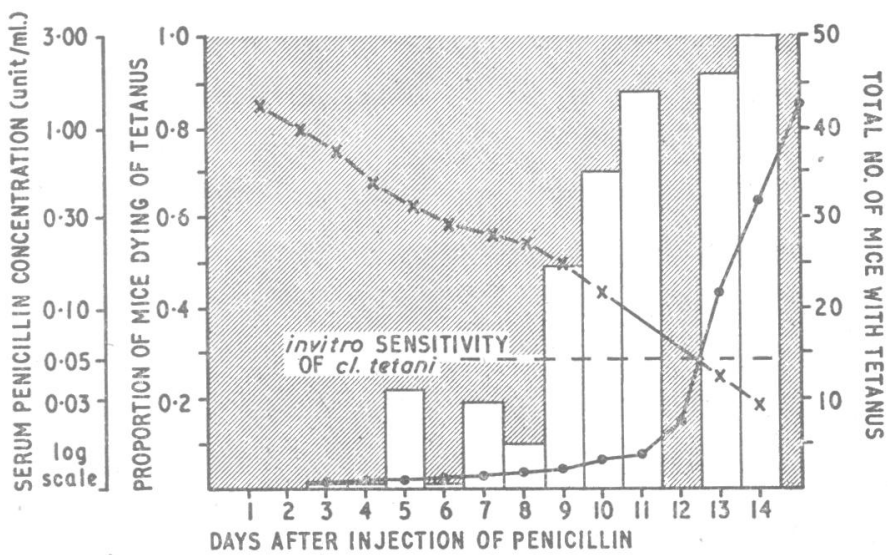

Serum penicillin concentration $(X-X)$; the proportion of mice dying following injection of tetanus spores (columns) at intervals after giving 10,000 units of benzathine penicillin. The total number of mice with signs of tetanus each day is also indicated (-).

It may be seen that a high proportion of those mice infected up to eight days after injection of the penicillin resisted tetanus. An increasing proportion of mice infected after this time died from tetanus, but the onset of the disease in these animals was delayed. Mice succumbing to the infection usually did not show signs of tetanus until the 13th day of the experiment, or occasionally the 12 th day, as may be seen in Table III, where the total number of mice which had signs of tetanus is recorded for each of the days. In the unprotected control mice signs first appeared 16 to 24 hours after injection of the spores, and it is therefore reasonable to believe that multiplication of tetanus bacilli starts approximately one day before signs are first evident. In the above experiment, therefore, multiplication probably started on the 12 th or occasionally the 11th daythat is, when the free penicillin concentration in the serum had fallen to below 0.1 unit $/ \mathrm{ml}$. However, as may be seen in the Chart, it was only when the serum-penicillin concentration remained above approximately $0.1 \mathrm{unit} / \mathrm{ml}$. for at least three to four days that tetanus was completely prevented. Since a serum-penicillin concentration of $0.1 \mathrm{unit} / \mathrm{ml}$. appeared to be effective in checking the growth of the tetanus bacilli in vivo and $0.05 \mathrm{unit} / \mathrm{ml}$. inhibited growth in vitro, it is probable that penicillin penetrates fairly freely into the developing anaerobic lesion.

\section{Reactivation of Infection in Mice Protected by Penicillin}

Although mice can be protected against tetanus by maintaining an adequate serum concentration of penicillin for three to four days, the possibility was considered, in view of the results of the in vitro experiments, that tetanus spores may still survive at the site of injection.

In order to test this poss bility 28 mice were injected with a minimum lethal dose of $\mathrm{Cl}$. tetani spores in calcium chloride, and immediately afterwards 22 of them were injected with

Table III.-Serum Penicillin Concentration and Protection Against Tetanus in Mice at Intervals After Injecting Benzathine Penicillin

\begin{tabular}{|c|c|c|c|c|c|c|c|c|c|c|c|c|c|c|c|c|}
\hline & & \multicolumn{15}{|c|}{ Days after Injection of 10,000 Units of Benzathine Penicillin } \\
\hline & & 1 & 2 & 3 & 4 & 5 & 6 & 7 & 8 & 9 & 10 & 11 & 12 & 13 & 14 & 15 \\
\hline $\begin{array}{l}\text { Average serum penicillin in } 6 \text { mice (units } / \mathrm{ml} \text {.) } \\
\text { Proportion of mice dying from tetanus } \\
\text { Total proportion of mice with signs of tetanus } \\
\text { Proportion of control mice dying from tetanus }\end{array}$ & $\begin{array}{l}\cdots \\
\cdots \\
\cdots\end{array}$ & E & $\begin{array}{l}1 \cdot 0 \\
=\end{array}$ & $\begin{array}{l}0.7 \\
0 / 9 \\
0 / 9 \\
5 / 5\end{array}$ & $\begin{array}{l}0.44 \\
0 / 10 \\
0 / 19 \\
5 / 5\end{array}$ & $\begin{array}{l}0 \cdot 37 \\
2 / 9 \\
0 / 28 \\
5 / 5\end{array}$ & $\begin{array}{l}0 \cdot 29 \\
0 / 9 \\
0 / 37 \\
5 / 5\end{array}$ & \begin{tabular}{l|}
$0 \cdot 25$ \\
$2 / 10$ \\
$1 / 47$ \\
$5 / 5$
\end{tabular} & $\begin{array}{l}0 \cdot 23 \\
1 / 10 \\
1 / 57 \\
5 / 5\end{array}$ & $\begin{array}{l}0 \cdot 16 \\
5 / 10 \\
2 / 67 \\
5 / 5\end{array}$ & $\begin{array}{l}0 \cdot 12 \\
7 / 10 \\
3 / 77 \\
5 / 5\end{array}$ & $\begin{array}{l}\overline{7 / 8} \\
4 / 85 \\
5 / 5\end{array}$ & $\begin{array}{l}- \\
\overline{8 / 85} \\
5 / 5\end{array}$ & $\begin{array}{r}0.04 \\
9 / 10 \\
22 / 95 \\
5 / 5\end{array}$ & $\begin{array}{l}0.03 \\
10 / 10 \\
32 / 105 \\
5 / 5\end{array}$ & $\bar{E}$ \\
\hline
\end{tabular}


a mixture of benzyl, procaine, and benzathine penicillins containing 20,000 units of penicillin. All the 22 mice given penicillin remained well, while the six control mice died of tetanus within two days. Fourteen days after infection the treated mice were reinjected at the originally infected site with $0.2 \mathrm{ml}$. of $5 \%$ calcium chloride. Fatal tetanus developed in seven of the mice (approximately 30\%) within five days and the $C l$. tetani organisms recovered from them had the same penicillin-sensitivity by in vitro tests as the original infecting strain. These experiments clearly showed that, although mice can be protected against tetanus with penicillin, spores can nevertheless survive in the tissues to produce tetanus when some activating stimulus occurs.

\section{Comparison of Antitoxin and Penicillin Prophylaxis in Mice}

It should be expected that penicillin would be incapable of preventing tetanus if given after toxin had been produced at the site of infection in an amount sufficient to cause symptoms. Antitoxin, on the other hand, should be able to prevent tetanus later in the course of the pathological process-that is, until toxin had reached the central nervous system and become inaccessible to neutralization by circulating antitoxin. An experiment was made in mice to investigate the period after infection for which the two methods of prophylaxis remain effective.

Eighty-eight mice were infected with tetanus spores and at intervals afterwards groups of eight were treated with either antitoxin or penicillin. The dose of antitoxin employed was 500 units, which was the smallest dose capable of fully protecting infected mice. The dose of penicillin used was 20,000 units in the form of the benzyl, procaine, and benzathine penicillin mixture; this was 10 times the minimum protective dose, but an excess was chosen to ensure that penicillin had every advantage. The results are given in Table IV.

TABLE IV.-Comparison of Penicillin and Antitoxin Prophylaxis at Intervals After Infection of Mice with Cl. tetani

\begin{tabular}{c|c|c}
\hline $\begin{array}{c}\text { Hours after Infection } \\
\text { when Prophylaxis Given }\end{array}$ & \multicolumn{2}{|c}{ Proportion of Mice Surviving after Injection of: } \\
\cline { 2 - 3 } & 500 Units Antitoxin & $\begin{array}{c}20,000 \text { Units Penicillin } \\
\text { (long-acting) }\end{array}$ \\
\hline 4 & $-7 / 8$ & $7 / 8$ \\
8 & $8 / 8$ & $2 / 8$ \\
16 & $8 / 8$ & $0 / 8$ \\
20 & $4 / 8$ & $0 / 8$ \\
24 & $0 / 8$ & $0 / 8$ \\
28 & $0 / 8$
\end{tabular}

It can be seen that antitoxin was effective when given 20 hours after infection, whereas penicillin was no longer able to prevent the onset of tetanus when given later than four hours after infection.

\section{Action of Penicillin on Cl. tetani Infection in the Presence of Penicillinase-producing Staphylococci}

The possibility that penicillin may fail to protect when penicillinase-producing organisms are present at the site of infection was examined in mice. One group of mice was injected with a minimum lethal dose of tetanus spores suspended in a $1 / 2$ dilution of an 18-hour culture of a penicil-

Table V.-Effect of Penicillin in Mice Infected with Cl. tetani Spores and Penicillinase-producing Staphylococcus aureus

\begin{tabular}{l|c|c|c}
\hline \multirow{2}{*}{ Treatment } & \multicolumn{2}{|c}{ Proportion of Mice Dying after Injection of: } \\
\cline { 2 - 4 } & Cl. tetani & $\begin{array}{c}\text { Cl. tetani and } \\
\text { Staph. aureus }\end{array}$ & Staph. aureus \\
\hline $\begin{array}{l}\text { 20,000 units penicillin } \\
\text { (long-acting) }\end{array}$ & $\begin{array}{l}1 / 9 \\
9 / 9\end{array}$ & $\begin{array}{l}10 / 10 \\
10 / 10\end{array}$ & $\begin{array}{l}0 / 5 \\
0 / 5\end{array}$ \\
\hline
\end{tabular}

All deaths were from tetanus. linase-producing strain of Staphylococcus aureus. A second group of mice was given a minimum lethal dose of the tetanus spores, and a third group a $1 / 2$ dilution of the staphylococcus culture. All preparations contained $2.5 \%$ calcium chloride, and the injection volume was $0.2 \mathrm{ml}$. Half the mice in each group were given within 10 minutes an intramuscular injection of 20,000 units of penicillin in the form of the benzyl, procaine, and benzathine penicillin mixture. The results, given in Table $\mathrm{V}$, suggest that penicillin may be ineffective in preventing multiplication of tetanus bacilli in a wound which is also infected with penicillinase-producing bacteria.

\section{Discussion}

These results, obtained from experiments in mice, support the view that penicillin may provide effective prophylaxis against tetanus for injured patients who have not been actively immunized. The results also show, however, that certain factors should be taken into account in considering the use of penicillin for this purpose.

Antibiotic prophylaxis can be effective only if naturally occurring strains of $\mathrm{Cl}$. tetani are sensitive, and, although the laboratory strains examined in this study proved to be penicillin-sensitive, resistant strains have been encountered by others. It is important that more investigations are made to see if such strains commonly occur.

The experiments reported here have shown that, in order to prevent tetanus in mice, penicillin prophylaxis should be started soon after the injection of spores and an adequate concentration maintained in the plasma for at least three to four days. It therefore seems reasonable to suggest that when penicillin prophylaxis is used in man it would be wise to give the antibiotic as soon as possible after injury and to ensure that it remains in the circulation for at least four days. The results also suggest that penicillin penetrates fairly freely into the developing anaerobic lesion and that the serum-penicillin concentration necessary to inhibit multiplication of $\mathrm{Cl}$. tetani need not be very much greater than the in vitro sensitivity of the infecting strain. A further point to be considered is that penicillin may be unreliable in wounds also infected with penicillinase-producing bacteria. In the prophylaxis of obviously contaminated wounds, therefore, antibiotics other than penicillin may be preferable.

It has been clearly shown in mice that tetanus may occur late after infection even though penicillin has been given, owing to the ability of spores to survive exposure to penicillin in vivo. The same situation may also occur in man, and the possibility that such cases can be prevented by active immunization first started at the time of injury has already been explored (Smith, 1964a, 1964b). It was shown, in both mice and guinea-pigs, that resistance to infection with tetanus spores develops 10 to 12 days after one dose of toxoid and is associated with the first appearance of antitoxin in the serum. Furthermore, it was shown that antitoxin usually becomes detectable in the serum of man within four weeks of giving one dose of adsorbed toxoid, although not after plain toxoid. It is therefore suggested that, when penicillin prophylaxis is used, adsorbed tetanus toxoid should be given at the same time. This measure would probably contribute to the prevention of tetanus developing later after injury, and would, in addition, provide the first injection of a full course of active immunization.

\section{Summary}

Each of 22 strains of $\mathrm{Cl}$. tetani was found to be inhibited in vitro by 0.05 unit of penicillin per ml., but a proportion of the organisms of each strain survived exposure to penicillin with their properties unchanged.

In order to control experimental infection in mice with penicillin it was found necessary to maintain the serum-penicillin 
concentration above the in vitro sensitivity level for at least three to four days.

Although $\mathrm{Cl}$. tetani infection in mice could effectively be controlled with penicillin, spores could nevertheless survive in the tissues and be reactivated to cause fatal tetanus.

Penicillin was unable to prevent tetanus in mice when given late after infection, at a time when antitoxin was effective.

Experiments in mice showed that penicillin failed to prevent tetanus when the spores were injected together with penicillinaseproducing staphylococci.

It is suggested that non-immune wounded persons who receive penicillin prophylaxis should also be given at the same time an injection of adsorbed tetanus toxoid which would serve as the first dose of a full course of active immunization.

Thanks are due to Dr. H. E. L'Etang, of Wyeth Laboratories, for the gift of both long-acting penicillin preparations.

\section{REFERENCES}

Anwar, A. A., and Turner, T. B. (1956). Bull. fohns Hopk. Hosp., 98, 85 .
Bigger, J. W. (1944). Lancet, 2, 497.

Bliss, E. A., Warth, P. T., and Chandler, C. A. (1950). Ann. N.Y. Acad. Sci., 53, 277.

Bruce, D. (1920). f. Hyg. (Camb.), 19, 1.

Cox, C. A., Knowelden, J., and Sharrard, W. J. W. (1963). Brit. med. f., 2, 1360 .

Dienes, L. (1950). Proc. Soc. exp. Biol. (N.Y.), 75, 412.

Evans, D. G., Fuller, A. T., and Walker, J. (1945). Lancet, 2, 336.

Filler, R. M., and Ellerbeck, W. (1960). f. Amer. med. Ass., 174, 1.

Garrod, L. P. (1958). f. roy. Army med. Cps, 104, 209.

Lennert-Petersen, O. (1954). Acta path. microbiol. scand., 35, 591.

Lindberg, R. B., and Newton, A. (1954). In Antibiotics Annual, 1954-55, p. 1059, edited by $H$. Welch and F. Martin-Ibañez. Medical Encyclopaedia Inc., New York, U.S.A.

McDonald, R. T., Chaikof, L., and Truant, J. P. (1960). Surg. Gynec. Obstet., 110, 702.

Novak, M., Goldin, M., and Taylor, W. I. (1949). Proc. Soc. exp. Biol. (N.Y.), 70, 573.

Scheibel, I., and Assandri, J. (1959a). In Proceedings of an International Symposium of Immunology, p. 381. Opatija, Yugoslavia.

- (1959b). Acta path. microbiol. scand., 46, 333.

Smith, J. W. G. (1964a). Brit. med. f., 1, 373.

(1964b). In Proceedings of the Ninth International Congress of Microbiological Standardization, Lisbon, 1964. Karger, Basle/New York. In press.

Welch, H. (1948). In Methods in Medical Research, 1, pp. 1-65, edited by V. R. Potter. Year Book Publishers, Chicago.

\title{
Prodromal Phase of Measles: Some Neurophysiological Studies
}

\author{
G. PAMPIGLIONE,* M.D., M.R.C.P.
}

\section{Brit. med. F., 1964, 2, 1296-1300}

Measles is one of the most widespread diseases in the world, and in the United Kingdom it reappears in large epidemics every two years, though more of ten in small epidemics. In other countries yearly epidemics are reported (Morley, Woodland, and Martin, 1963). Probably the most striking feature in the course of measles is the appearance of the rash. The illness, however, as recognized by the patient, his relatives, and the medical practitioner, begins a few days before the appearance of the rash. As recognized by the virologist it begins even earlier (Enders, 1962). Very little is known about the cause of the rash and why it becomes established at a particular phase of the illness, during which the virus disappears rapidly.

The mechanisms responsible for some of the "complications" of measles are poorly understood, although it is generally recognized that each epidemic may differ from others. The figure of about $0.9 / 1,000$ for the neurological complications of measles, calculated by Miller, Stanton, and Gibbon (1956) as the average for 15 epidemics, is not grossly different from the figure given by Robbins (1962) and by La Boccetta and Tornay (1964). However, in a recent survey in the United Kingdom, Miller (1964) suggests a figure of 4/1,000 for all the neurological complications of measles during the 1963 epidemic. The overall mortality in cases of measles encephalitis collected from the literature reported by Miller et al. (1956) varied from $27 \%$ to $15 \%$. A mortality of $26 \%$ has been reported by Holler (1964) out of his 30 cases of measles encephalitis in children.

In the course of an epidemic of measles in England in 1963 neurophysiological studies were made on a total of 104

\footnotetext{
* Physician, Department of E.E.G. and Clinical Neurophysiology, the Hospital for Sick Children and the Royal Free Hospital, London.
}

patients. While the bulk of this work was carried out during and after the appearance of the rash and will be reported elsewhere (Pampiglione, Ramsay, Williams, and Young, 1964), the present paper describes some electroencephalographic (E.E.G.) observations made on a group of children who were examined a few days before rather than after the appearance of the measles rash. This study was made to assess the possible extent of the alteration of cerebral function in apparently uncomplicated cases of measles, during a period of the disease-the " prodromal phase"-which has until now been incompletely studied.

\section{Material}

In view of the fact that the incubation period of measles does not usually exceed 14 days, children who had E.E.G. studies two weeks or more before the appearance of the rash were not included in the present investigation. A total of 22 children had E.E.G. studies during the incubation period-that is to say, between 1 and 14 days before the appearance of the rash-and could be re-examined either during or after the end of the disease. The material was collected in the course of various E.E.G. studies in children as follows (see also Chart):

(a) Five normal children, known measles contacts (1963 epidemic), admitted to hospital (Coppetts Wood) during the prodromal phase for social reasons. These had E.E.G.s either two days or one day before the rash appeared and were retested during and after the rash.

(b) Eight normal children studied during a survey in London day nurseries (Medical Research Council project). These were tested from 11 to 3 days before the rash appeared (1963 epidemic) and retested once or twice one to three months after the rash. 